\author{
수직평판의 거칠기가 자연대류 열전달에 미치는 영향 \\ 옥승민 · 정범진 ${ }^{\dagger}$ \\ 경희대학교 원자력공학과 \\ (2014년 5월 8일 접수, 2014년 5월 21일 수정, 2014년 5월 21일 채택)
}

\title{
The Influence of the Surface Roughness on the Natural Convection on a Vertical Flat Plate
}

\author{
Seung-Min Ohk $\cdot$ Bum-Jin Chung ${ }^{\dagger}$ \\ Kyung Hee University
}

(Received 8 May 2014, Revised 21 May 2014, Accepted 21 May 2014)

요 약

\begin{abstract}
수직평판의 거칠기에 따른 자연대류 열전달의 변화를 실험적으로 측정하였다. 열전달 실험을 대신하 여 유사성에 기초한 물질전달로 모사하여 실험을 수행하였다. 또한 국부적인 열전달률을 알기위해 Piecewise electrode를 채택하였다. $\operatorname{Pr}$ 수는 2,014 그리고 높이(L)는 $0.154 \mathrm{~m}$ 로 고정하고 매끈한 수직평 판에 대해 실험을 수행한 결과 Le Fevre의 수직평판 상관식과 거의 일치하였다. 거칠기 정도를 $0.5 \mathrm{R}_{z} \mu \mathrm{m}$ $\sim 14.1 \mathrm{R}_{z} \mu \mathrm{m}$ 로 변화시켰을 때 $\mathrm{Nu}_{\mathrm{L}}$ 수는 거칠기 정도가 커지면서 증가하는 경향을 나타내었다. 실험결 과는 간단한 상관식으로 정리하였다.
\end{abstract}

주요어 : 수직평판, 자연대류, 거칠기, 상사성, 전기도금시스템, 열전달

\begin{abstract}
The influence of the surface roughness on the natural convection heat transfers of a vertical plate were measured experimently. Mass transfer experiments instead of heat transfer experiment were performed based on the analogy. The piecewise electrodes were adopted to measure the local-average Nusselt number. Prandtl number was 2,014 and height of the plate was $0.154 \mathrm{~m}$ The test results for a smooth surface showed similar heat transfer rate with the Le Fevre heat transfer correlation for a vertical plate. The Nusselt number increased with the roughness $\mathrm{Rz} 0.5 \sim 14.1 \mu \mathrm{m}$. The test results were presented by a simple correlation.
\end{abstract}

Key words : Vertical plate, Natural convection, Analogy, Electroplating system, Heat transfer

1. 서 론

후쿠시마 원전사고 이후, 전원의 상실시에도 자연 력에 의존하여 가동되는 피동냉각계동(Passive cooling system)의 채택이 증가하고 있다. 이에 따라 서 자연대류 열전달에 대한 연구도 증가하고 있다. 특히, 원전과 같은 고부력 조건의 자연대류에 대해서

\footnotetext{
${ }^{\dagger}$ To whom corresponding should be addressed.

Department of Nuclear Engineering, Kyunghee University

Tel : 031-201-3893 E-mail : bjchung@khu.ac.kr
}

는 실험적인 연구가 많이 수행되지 않았다.

표면 거칠기에 따른 열전달에 관한 연구는 몇몇 학 자들에 의하여 수행되어 왔지만 주로 강제대류에 대 해 수행되었고, 자연대류에서는 난류영역에 한정되어 있다(1-3). 따라서 층류 자연대류 영역에서 수직평판의 거칠기 변화가 경계층 발달에 어떠한 영향을 미치고, 열전달 향상에 얼마나 기여하는지에 대한 연구가 필 요하다.

수직평판에서 거칠기는 열전달 표면적을 향상시켜 열전달률을 증가시킨다. 그리고 거칠기의 영향은 경 
계층 두께가 가장 얇은 수직벽면의 유동의 시작부분 (Leading edge)에서 확연하게 나타난다(4).

본 연구에서는 수직평판의 거칠기 정도에 따른 자 연대류 열전달 현상을 측정하였다. 유사성(Analogy) 의 원리를 이용하여 물질전달 실험으로 모사하였다. 물질전달계로 황산-황산구리 $\left(\mathrm{H}_{2} \mathrm{SO}_{4}-\mathrm{CuSO}_{4}\right)$ 수용액 의 전기도금계를 채택하여 물질전달계수를 측정하였 다. 가열벽면(Heated wall)으로 모사되는 음극 (Cathode)의 전체높이는 $0.154 \mathrm{~m}$ 이고 너비는 $0.01 \mathrm{~m}$ 이다, 음극은 높이 $0.003 \mathrm{~m}$ 의 5 개 Piecewise electrode 를 채택하여 국부평균(Local-average) $\mathrm{Nu}_{\mathrm{L}}$ 값을 측정 할 수 있도록 하였다 이때 $\mathrm{Ra}_{\mathrm{L}}$ 수는 3.1×1011으로 층류 영역에 해당한다. Pr 수는 2,014로 고정하였으 며, 표면 거칠기는 여러 가지 사포를 이용하여 변화 를 주었다.

\section{2. 이론적 배경}

\section{2-1. 직평판에서의 자연대류}

자연대류는 온도차 또는 농도차에 의하여 발생하 는 부력이 그 유체의 점성 및 확산을 극복할 때 나타 난다. 이와 같이, 자연대류는 외력에 의해서 구동되는 것이 아니라 온도차 또는 농도차에 의해서 발생하는 유동이다. Fig. 1은 열전달계에서 온도차로 발생한 부력에 의해 유체의 순환(자연대류)이 일어나는 메커 니즘을 나타낸다. $T_{0}$ 인 가열벽 근처에서 유체가 가 열되면 밀도가 감소하며 부력으로 인해 상승한다. 상 승하여 확산된 유체는 $T_{\infty}$ 인 냉각벽에 의해 냉각되 고 압축된다. 따라서 밀도가 증가한 유체는 하강하게 된다. 이와 같이 풀 $(\mathrm{Pool})$ 내에서 자연대류는 Heat engine cycle과 같이 순환하는 거동을 나타낸다.

수직평판 자연대류 열전달에서는 $\mathrm{Gr}_{\mathrm{L}}$ 수 $10^{9}$ 을 기 준으로 층류 $\left(\mathrm{Gr}_{\mathrm{L}}<10^{9}\right)$ 와 난류 $\left(\mathrm{Gr}_{\mathrm{L}}>10^{9}\right)$ 로 구분할 수 있으며, 이에 대한 두 가지 열전달 상관식은 다음 과 같다(5).

$$
\begin{aligned}
& \text { Le Fevre } N u_{a v}=0.67\left(G r_{L} P r\right)^{0.25} \text { at } \quad G r<10^{9} \\
& \text { Fouad } N u_{a v}=0.31\left(G r_{L} P r\right)^{0.28} \text { at } \quad G r>10^{9}
\end{aligned}
$$

\section{2-2. 표면 거칠기에 따른 자연대류 열전달}

수직평판에서 거칠기 영향에 따른 자연대류 열전 달 연구는 많은 학자들에 의해서 수행되었다(6-11).

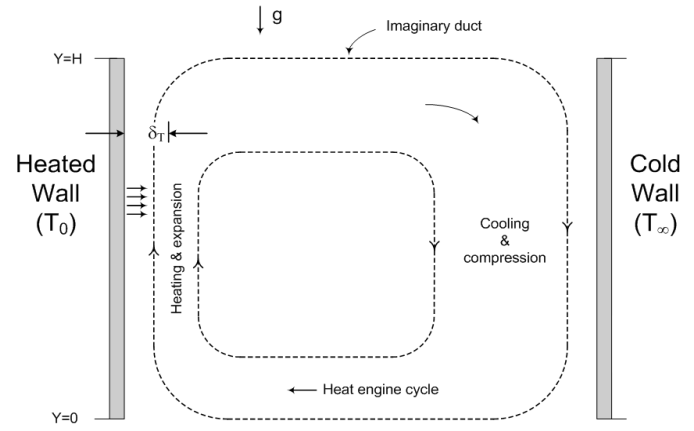

Fig. 1. Fluid circulation induced by temperature difference.

$\mathrm{Yao}^{(6)}$ 는 표면이 Sine파 형상인 수직판에서의 자연 대류 열전달을 수치적으로 계산하였다. 표면의 거칠 기를 변화시킨 결과 열전달률이 수직평판(Smooth plate) 보다 최대 두 배 정도 증가한다고 하였다. 또한 굴곡진 수직판(Rough plate)은 자연대류에서 조기에 천이상태를 야기 할 수 있다고 하였다. Fage와 Preston $^{(7)}$ 은 표면의 거칠기 정도가 심할수록(Peak의 높이가 높을수록) 천이 지점이 수직판의 하단으로 이 동한다고 하였다.

Tetsu Fujii 등(8)은 물과 Spindle oil에 대하여 RaL 수 1010 1015에서 수직 원형관 표면의 거칠기에 따 른 열전달 실험을 수행하였다. 그 결과 난류상태에서 거칠기 정도에 따라 국부 열전달은 최대 $10 \%$ 차이가 난다고 하였다.

Shakerin 등(9)은 Rectangular fin 형태로 거칠기 요 소를 주어 $\operatorname{Pr}$ 수 $0.7, \mathrm{Ra}_{\mathrm{L}}$ 수 $10^{5} \sim 10^{8}$ 의 조건에서 층 류 자연대류 열전달을 수치적 그리고 실험적으로 연 구하였다. 염료를 물에 투입하여 유동을 시각화하였 으며, 수직판의 상단에서는 거칠기 영향이 열전달 변 화에 효과가 없다고 보고하였다. 또한 거칠기 효과를 주어 열전달 면적이 증가했음에도 불구하고 총 열전 달률은 수직평판(Smooth plate)의 열전달률과 유사했 다. 이는 Rectangular fin 사이에 Stagnant region이 존재하기 때문에 오히려 부분적으로 열전달을 감소시 키기 때문이라고 보고하였다. Acharya와 Mehrotra ${ }^{(10)}$ 역시 Ribbed 기하구조에 대하여 Rib과 Rib 사이에 고여있는 영역(Dead region)이 존재하여 수직판보다 열전달이 감소한다고 하였다.

Dryden $^{(11)}$ 은 수직판에서 거칠기는 경계층을 불안 정하게 만들어 총 열전달에 영향을 준다고 언급하였 다. 
Table 1. Dimensionless group for analogy system.

\begin{tabular}{c|c}
\hline Heat transfer & Mass transfer \\
\hline \hline Prandtl No. $\frac{\nu}{\alpha}$ & Schmidt No. $\frac{\nu}{D}$ \\
\hline Nusselt No. $\frac{h_{m} L}{k}$ & Sherwood No. $\frac{h_{m} L}{D}$ \\
\hline Rayleigh No. & Rayleigh No. \\
$\frac{g \beta \Delta T L^{3}}{\alpha \nu}$ & $\frac{g L^{3}}{D \nu} \frac{\Delta \rho}{\rho}$ \\
\hline
\end{tabular}

\section{2-3. 전기도금계를 이용한 유사성 실험방법}

열전달과 물질전달 시스템은 초기 및 경계조건이 같으면 수학적으로 서로 유사(Analogous)하기 때문 에 열전달 문제를 물질전달 문제로 변환할 수 있다. 이러한 물질전달계와 열전달계의 무차원수 관계는 Table 1에 나타내었다. 본 연구에서는 황산-황산구리 $\left(\mathrm{H}_{2} \mathrm{SO}_{4}-\mathrm{CuSO}_{4}\right)$ 수용액의 전기도금계를 물질전달계로 선택하였다.

전기도금계(Electroplating system)의 한계전류를 이용한 전달현상에 대한 연구는 Levich ${ }^{(12)}$ 에 의해 시 도되었으며 Selman and Tobias ${ }^{(13)}$ 은 여러 조건에서 의 물질전달 상관식을 체계적으로 정립했다. Chung $^{(14)}$ 등은 수평평판에서의 강제대류와 수직벽면 에서의 자연대류 열전달 현상에 관하여 전기도금계를 이용한 실험방법론을 적용하여 기존에 알려진 열전달 상관식을 예측할 수 있음을 검증하였다. 유사성을 이 용한 실험기법에 대한 보다 자세한 설명은 Chung ${ }^{(14)}$ 과 $\mathrm{Kang}^{(15)}$ 의 논문에 제시되어 있다.

\section{2-4. 한계전류기법}

열전달계에서의 열전달계수를 구하기 위해 벽면 온도와 평균 유체온도를 알아야 된다. 마찬가지로 물 질전달계에서의 물질전달계수를 구하기 위해선 벽면 농도와 평균 유체농도를 알아야 한다. 그러나 전기도 금계에서 음극표면에서의 구리이온의 농도를 알기 어 렵다. 이와 같은 문제는 한계전류기법을 사용하여 해 결할 수 있다. 황산구리 수용액에 담겨진 구리 양극 과 구리음극에 인가된 전압을 증가시키면서 측정한 전류를 Fig. 2에 나타내었다. 전기도금계에서 전극사 이에 인가된 전위차를 증가시키면 측정된 전류는 증 가하다가 더 이상 증가하지 않는 플레이토우(Plateau) 영역에 도달하며 이때의 전류를 한계전류(Limiting current)라 한다. 이는 양극에서 발생된 구리이온이 음극으로 전달되는 속도보다 음극에서 구리이온이 전 자를 얻어 환원되는 속도가 빨라짐에 따라 발생하는 현상이며 한계전류에 이르면 음극표면에서의 구리이 온 농도를 0 으로 취급할 수 있다. 따라서 물질전달계 수(Mass coefficient), $\mathrm{h}_{\mathrm{m}}$ 은 식(3)에 따라 모액농도 (Bulk concentration), $\mathrm{C}_{\mathrm{b}}$ 와 한계전류밀도(Limiting current), $\mathrm{I}_{\lim }$ 만으로 구할 수 있다(16).

$$
h_{m}=\frac{\left(1-t_{n}\right) I_{\text {lim }}}{n F C_{b}}
$$

\section{3. 실험}

\section{3-1. 실험장치 및 실험범위}

Fig. 3은 실험장치와 그 회로의 개략도이다. 실험 장치는 아크릴로 제작되었으며 양극평판과 음극평판 이 마주보고 있는 형태이다. 음극판은 가로 $0.01 \mathrm{~m}$ 높이 $0.03 \mathrm{~m}$ 의 구리판을 $0.001 \mathrm{~m}$ 간격으로 하여 세로 방향으로 5 개를 부착하였고. 양극판은 가로 $0.03 \mathrm{~m}$

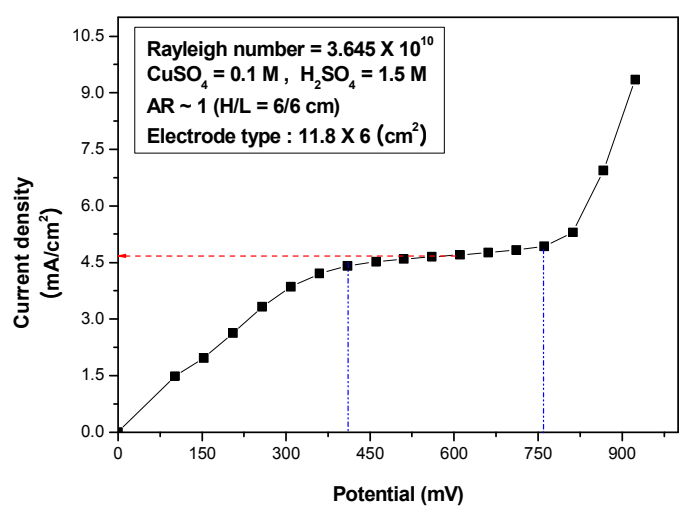

Fig. 2. Typical limiting current density curve.

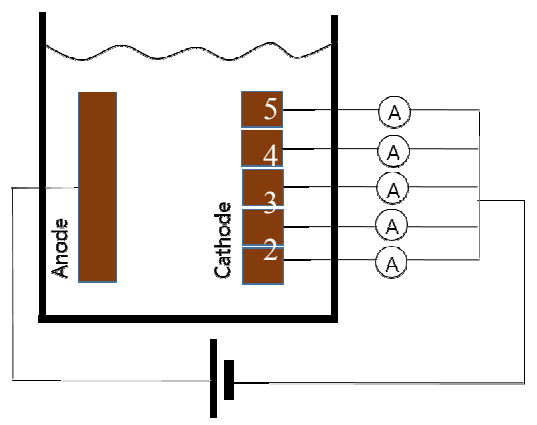

Fig. 3. The experimental equipments and system circuit. 
Table 2. Test matrix for Roughness effect in natural convection.

\begin{tabular}{|c|c|c|c|c|c|}
\hline $\operatorname{Pr}$ & $\mathrm{L}(\mathrm{m})$ & Electrodes & $\mathrm{RaL}$ & $\mathrm{GrL}$ & $\mathrm{Rz}(\mu \mathrm{m})$ \\
\hline \multirow{5}{*}{2,014} & \multirow{5}{*}{0.154} & 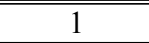 & $2.29 \times 109(1)$ & $1.13 \times 106$ & \multirow{5}{*}{$0.5,1.5,2.8,8.5,11.6,14.1$} \\
\hline & & 2 & $1.83 \times 1010(1 \sim 2)$ & $6.09 \times 106$ & \\
\hline & & 3 & $6.18 \times 1010(1 \sim 3)$ & $3.07 \times 107$ & \\
\hline & & 4 & $1.46 \times 1011(1 \sim 4)$ & $7.47 \times 107$ & \\
\hline & & 5 & $2.86 \times 1011(1 \sim 5)$ & $1.42 \times 108$ & \\
\hline
\end{tabular}

$\mathrm{H}_{2} \mathrm{SO}_{4} \quad 1.5 \mathrm{M}, \mathrm{CuSO}_{4} \quad 0.05 \mathrm{M}$

세로 $0.1 \mathrm{~m}$ 의 구리판을 부착하였다. 각 시편에는 Fluke사의 $15 \mathrm{~B}$ Digital Multimeter를 연결하여 전류 를 측정하였고, 전원공급장치는 VüPOWER사의 DC Power supply-18B10을 이용하였다.

본 연구에서는 사포를 이용해서 시편 표면에 거 칠기를 주었으며, 거칠기를 나타내는 단위로 $\mathrm{Rz}$ 를 채 택하였다. Rz는 국제표준화기구(ISO) 단위로써 10점 평균 거칠기(The ten-point height parameter)이다. 거 칠기 정도 측정을 위해 $\mathrm{TAQ}$ 사의 SP-SP1560을 사용 하였다. 기준길이는 $10 \mathrm{~mm}$ 로 하였으며 거칠기 정도 는 5 회 측정한 평균값을 사용하였다.

Table 2는 실험범위를 나타낸다. Pr 수는 2,014 로, 수직평판의 길이 $(\mathrm{L})$ 는 $0.154 \mathrm{~m}$ 로 고정하였다. Single electrode의 높이는 $0.03 \mathrm{~m}$ 이고, Single electrode의 숫자가 증가할수록 수직평판의 상단에 위치된다. $\mathrm{Rz}$ 범위는 $0.5 \mu \mathrm{m} \sim 14.1 \mu \mathrm{m}$ 이다.

\section{3-2. 거칠기 정도에 따른 시편의 표면}

구리음극은 40\#, 120\#, 220\#, 320\# 및 400\# 사포 를 이용하여 거친 표면을 제작하였다. Fig. 4 (a) (d) 는 FE-SEM으로 촬영한 시편의 표면 사진이다. 5.0 $\mathrm{kV}$ 의 가속된 전자선을 사용하였으며 $\mathrm{WD}$ (시편과 대 물렌즈 사이거리)는 $7.9 \mathrm{~mm}$ 에서 100 배의 배율로 촬 영 하였다. Fig. 4(a) 는 거칠기 정도가 매우 작으며, 매끈한 평면(Smooth plate)과 거의 유사하다. Rz가 증가할수록 거칠기의 정도가 증가한다.

\section{4. 실험 결과 및 토의}

Fig. 5는 $\mathrm{RaL}$ 에 따른 $\mathrm{Nu}_{\mathrm{L}}$ 수를 나타낸다. 각 Symbol은 거칠기 정도 $(\mathrm{Rz})$ 를 의미하며, 가장 작은 거칠기 정도 $(\mathrm{Rz}=0.5)$ 에서의 $\mathrm{Nu}_{\mathrm{L}}$ 수는 수직평판 상관 식인 Le Fevre 상관식과 일치하였다. Rz가 증가할수 록, 실험결과의 $\mathrm{Nu}_{\mathrm{L}}$ 수는 Le Fevre 상관식보다 증가
하는 경향을 보였는데, 이는 거칠기 정도의 증가로 인해 열전달 면적이 증가했기 때문이라고 판단된다

Fig. 6은 5 개로 구분한 음극에서 측정된 국부평균 $\mathrm{Nu}_{\mathrm{x}}$ 수를 나타낸 것이다. 각 심볼은 거칠기 정도를 의미한다. 수직평판의 하단부에서 상단부로 갈수록 모든 $\mathrm{R}_{\mathrm{z}}$ 에서 국부평균 $\mathrm{Nu}_{\mathrm{x}}$ 수는 감소하였다. 이는 경 계층이 시작되는 하단부의 유동의 시작부분(Leading edge)에서 경계층 두께가 매우 얇기 때문에 거칠기 효과가 두드러지게 나는 것이라 판단된다.

유동의 시작부분(Leading edge) 근처의 전극에서 는 $\mathrm{R}_{\mathrm{z}}$ 에 따른 $\mathrm{Nu}_{\mathrm{x}}$ 값 차이가 크고, 높은 $\mathrm{Ra}_{\mathrm{x}}$ 에서는 $\mathrm{R}_{\mathrm{z}}$ 에 따른 $\mathrm{Nu}_{\mathrm{x}}$ 값 차이가 작았다. 이는 경계층이 얇 은 하단부에서 Nux값은 거칠기 정도의 영향을 크게 받고, 경계층이 두꺼운 상단부에서는 표면 거칠기가 $\mathrm{Nu}_{\mathrm{x}}$ 값에 크게 영향을 미치지 않는다고 판단된다.

Fig. 7은 거칠기 정도 $\left(\mathrm{R}_{\mathrm{z}}\right)$ 에 따른 $\mathrm{Nu}_{\mathrm{x}}$ 를 나타낸 것 이다. 각 심볼(Symbol)은 같은 $\mathrm{Ra}_{\mathrm{x}}$ 를 나타낸다. 여기 서 $\mathrm{x}$ 는 수직평판의 높이에 따른 위치를 나타낸다. 모 든 $\mathrm{R}_{\mathrm{z}}$ 에서 $\mathrm{Ra}_{\mathrm{x}}$ 수 $2.86 \times 108$ 과 $7.73 \times 109$ 에서 $\mathrm{Nu}_{\mathrm{x}}$ 값 차이는 상대적으로 나머지 $\mathrm{Ra}_{\mathrm{x}}$ 간의 $\mathrm{Nu}_{\mathrm{x}}$ 값 차이보다 컸다. 이는 수직평판 하단부에서는 경계층이 시작됨 으로써 열전달이 상승하고, 상단부로 갈수록 열전달 이 감소하기 때문이다. 또한 $\mathrm{R}_{\mathrm{z}}$ 가 증가할수록 $\mathrm{Ra}_{\mathrm{x}}$ 에 따른 $\mathrm{Nu}_{\mathrm{x}}$ 값 차이가 크게 나타났다. 이는 표면 거칠기 가 경계층을 발전시키는 것을 방해함으로써 $\mathrm{Nu}_{\mathrm{x}}$ 값을 상승시키는데 기여하였기 때문이라고 판단된다. 또한 거칠기 정도가 커질수록 각 층에서 $\mathrm{Nu}_{\mathrm{x}}$ 수는 증가하 는데 이를 통해 거칠기를 증가시키면 열전달이 향상 된다는 것을 알 수 있다.

Fig. 8은 $\mathrm{Ra}_{\mathrm{x}}$ 수에 따른 실험의 국부 평균 (Local-average) $\mathrm{Nu}_{\mathrm{x}}$ 값과 그에 따른 실험적 상관식 을 나타낸 것이다. 상관식에서 $\mathrm{Ra}_{\mathrm{x}}$ 를 고려함으로써 수직평판의 높이가 증가할수록 $\mathrm{Nu}_{\mathrm{x}}$ 값이 감소함을 나타내었다. 그리고 $\mathrm{R}_{\mathrm{z}}$ 의 영향을 추가함으로써 거칠 


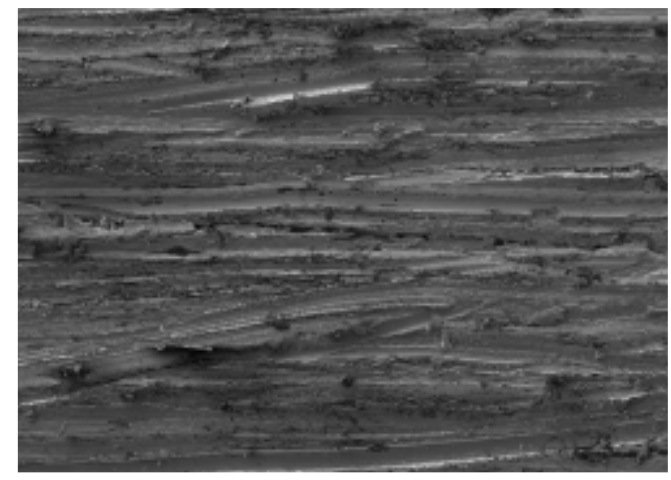

(a) $R_{z}=14.1$

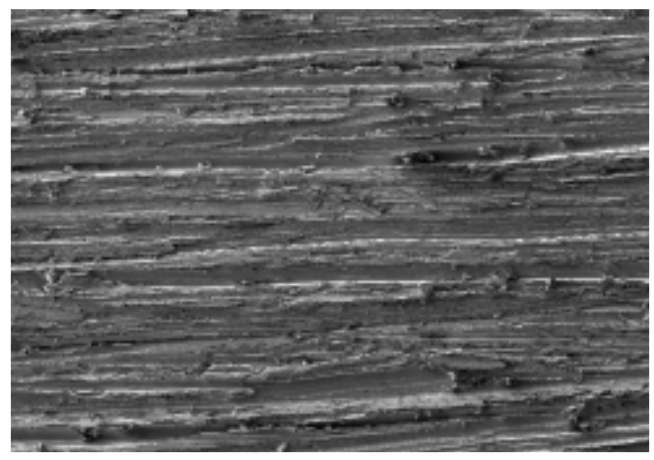

(b) $R_{z}=11.5$

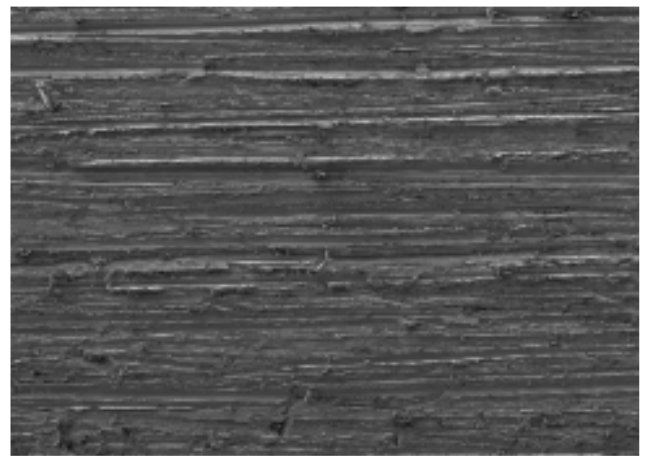

(c) $R_{z}=8.5$

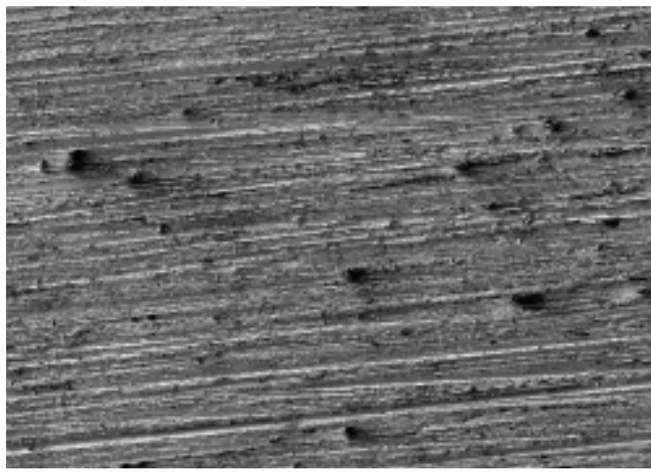

(d) $R_{z}=2.8$

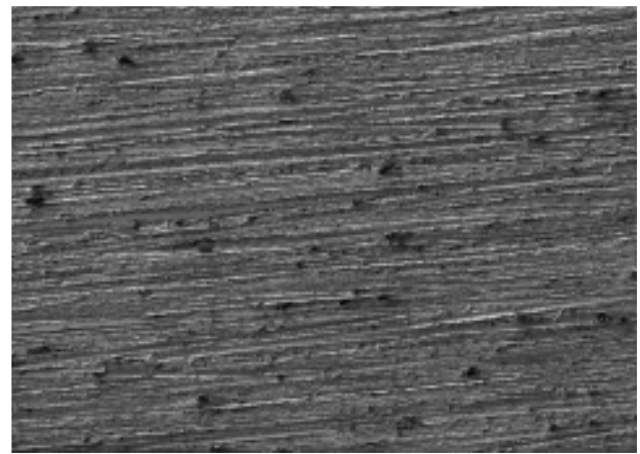

(e) $R_{z}=1.5$

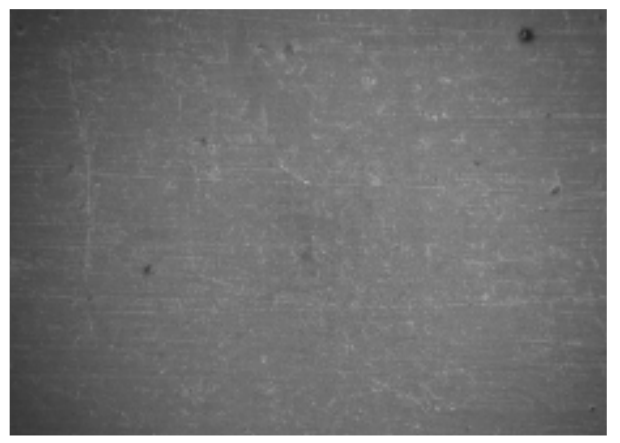

(f) $R_{z}=0.5$

Fig. 4. Roughness state of specimen of copper.

기 정도가 클수록 $\mathrm{Nu}_{\mathrm{x}}$ 값이 증가한다는 것을 나타내 었다. 상관식은 식(4)과 같다. 실험결과와 상관식의 평균오차는 $1.4 \%$ 이고, 최대 오차는 $2.7 \%$ 이다

$$
N u=\left(330.76+2.32 R_{z}\right) R a^{-0.051}
$$

\section{5. 결론}

수직평판의 표면에 거칠기 정도를 변화시키면서
자연대류 열전달을 실험적으로 연구하였다. 열과 물 질전달의 유사성(Analogy)에 기초하여 열전달 실험 을 물질전달 실험으로 대체하였고, 물질전달계로는 전기도금계를 채택하였다. 높이 $0.154 \mathrm{~m}$ 의 수직평판 을 5등분으로 나눈 Piecewise electrode를 채택하여 국부평균 $\mathrm{Nu}$ 값을 측정하였다. 이때 표면 거칠기는 $\mathrm{R}_{\mathrm{z}}$ $0.5 \sim 14.1 \mu \mathrm{m}$ 로 변화하여 실험하였다.

실험결과 거칠기 정도가 가장 작은 $\mathrm{R}_{\mathrm{z}} 0.5 \mu \mathrm{m}$ 의 수 직평판(Rough plate)에서 측정된 열전달률은 $\mathrm{Le}$ Fevre의 수직평판(Flat plate)에 대한 자연대류 상관 


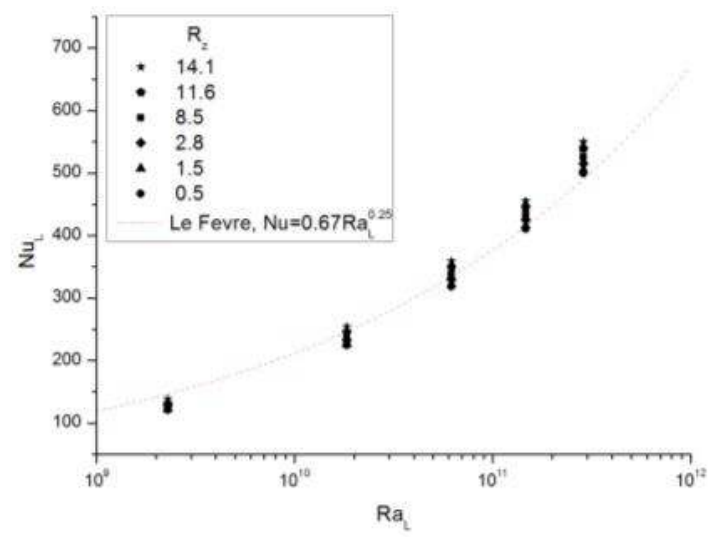

Fig. 5. Comparison test result with correlation.

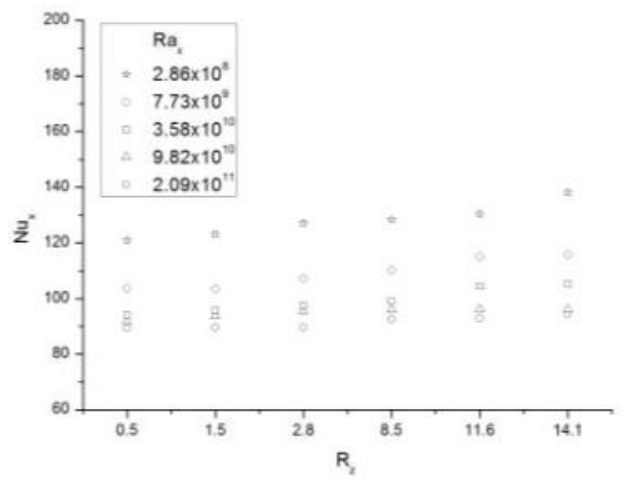

Fig. 7. Comparison the test result according to the roughness.

식과 유사하였다. 거칠기 정도를 높일수록 열전달률 은 향상하였는데, 이는 거칠기 정도가 증가할수록 표 면적이 증가했기 때문이다. 수직판의 국부평균 $\mathrm{Nu}$ 값 을 확인한 결과, 유동의 시작부분(Leading edge)에서 거칠기 정도에 따른 열전달률 차이가 가장 컸다. 이 는 유동의 시작부분에서 경계층의 두께가 매우 얇으 므로 표면 거칠기의 영향을 크게 받는 것으로 판단된 다. 수직평판의 상단에서는 경계층의 두께가 증가함 에 따라 거칠기에 따른 열전달률의 차이가 크지 않았 다.

실험결과를 토대로, 수직평판의 높이와 거칠기 정 도에 따른 실험 상관식을 개발하였다. 이는 실험결과 와 약 $1.4 \%$ 오차를 나타냈으며 실험결과와 거의 일 치한다.

\section{감사의 글}

본 연구는 2012년도 산업통상자원부의 재원으로

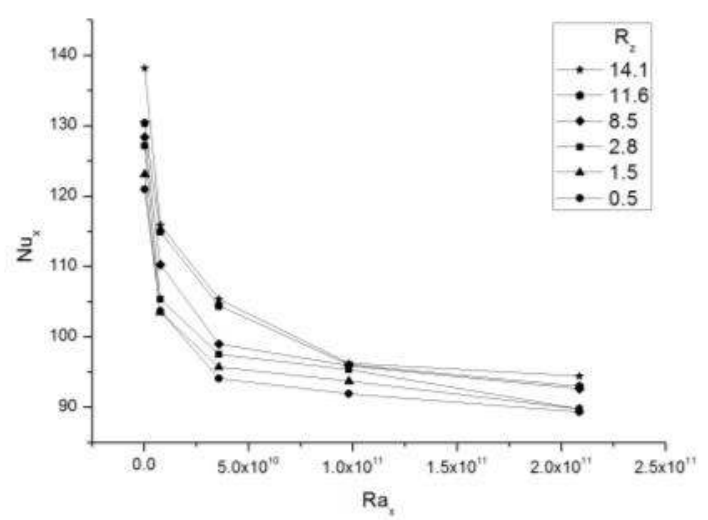

Fig. 6. Nusselt number depending on a length of the roughness effect.

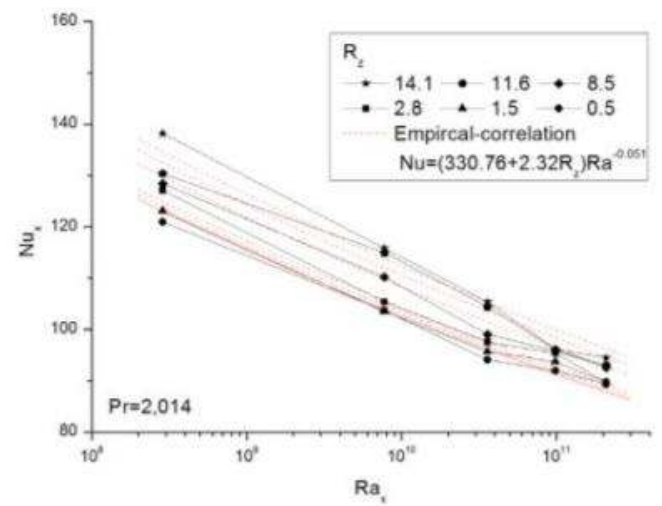

Fig. 8. Empirical correlation as Rax.

한국에너지기술평가원(KETEP)의 지원을 받아 수행 한 연구과제(No.20124030100080)입니다.

기호

$\mathrm{D}_{\mathrm{m}} \quad$ : 확산계수 $(\mathrm{m} / \mathrm{s} 2)$

$g$ : 중력가속도 $(9.8 \mathrm{~m} / \mathrm{s} 2)$

$\mathrm{Gr}_{\mathrm{L}}$ : Grashof 수

$\mathrm{h}_{\mathrm{h}}$ : 대류열전달계수 $(\mathrm{W} / \mathrm{m} 2 \cdot \mathrm{K})$

$\mathrm{h}_{\mathrm{m}} \quad$ : 물질전달계수 $(\mathrm{m} / \mathrm{s})$

: 열전도계수 $(\mathrm{W} / \mathrm{m} \cdot \mathrm{K})$

$\mathrm{L} \quad$ : 수직판의 높이 $(\mathrm{m})$

$\mathrm{Nu}_{\mathrm{L}}$ : Nusselt 수 $(\mathrm{hL} / \mathrm{k})$

$\mathrm{Nu}_{\mathrm{x}}$ : 국부 Nusselt 수 $(\mathrm{hx} / \mathrm{k})$

Pr : Prandtl 수

$\mathrm{Ra}_{\mathrm{L}} \quad$ : Rayleigh 수

$\mathrm{Ra}_{\mathrm{x}} \quad$ : 국부 Rayleigh 수

$\mathrm{R}_{\mathrm{z}} \quad: 10$ 점 평균 거칠기 $(\mu \mathrm{m})$ 


\section{Greek symbols}

$$
\begin{array}{ll}
\alpha & : \text { 열확산계수 }\left(\mathrm{m}^{2} / \mathrm{s}\right) \\
\beta & : \text { 부피팽창계수 }(1 / \mathrm{K}) \\
\nu & : \text { 동점성계수 }\left(\mathrm{m}^{2} / \mathrm{s}\right) \\
\rho & : \text { 밀도 }\left(\mathrm{kg} / \mathrm{m}^{3}\right)
\end{array}
$$

\section{References}

1. Cheesewright, R., Turbulent natural convection from a vertical plane surface, J. Heat Transfer, 1968, 90, 1-8.

2. Andreopoulos, J. and Wood, D. H., The response of a turbulent boundary layer to a short length of surface roughness, Journal of Fluid Mechanics, 1982, 118, 143-164.

3. Ligrani, P. M., Moffat, R. J. and Kays. W. M., Artificial thickened turbulent boundary layers for studying heat transfer and skin friction on rough surfaces, Journal of Fluids Engineering, 1983, 105, 146-153.

4. Mark W. Pinson and Ting Wang. Effects of leading-edge roughness on fluid flow and heat transfer in the transitional boundary layer over a flat plate, 1997, 40, 2813-2823.

5. Bejan, A., Convection Heat Transfer, 2nd ed., New York, John Wiley \& Sons, INC, 1994, 466-514.

6. Lun-Shin Yao, Natural convection along a vertical complex wavy surface, 2006, 49, 281-286.

7. Fage, A and Preston, J. H., On transition from laminar to turbulent flow in the boundary layer, Proceedings of the Royal Society of London, 1941, 178, 201-227.

8. Fujii, T., Fujii, M., and Takeushi, M., Influence of various surface roughness on the natural convection, 1973, 16, 629-640.

9. Shakerin, S., Bohn, M., Loehrke, R. I., Natural convection in an enclosure with discrete roughness elements on a vertical heated wall, 1988, 31, 1423-1430.

10. Acharya, S. and Mehrotra, A., Natural convection heat transfer in smooth and ribbed vertical channels, Int. J. Heat Mass Transfer, 1993, 36, 236-241.

11. Dryden, H. L., Review of published data on the effect of roughness on transition from laminar to turbulent flow, Journal of the Aeronautical Science, 1953, 20, 477-482.

12. Levich. V. G., Physicochemical Hydrodynamics, Prentice-Hall, Englewood Cliffs, N.J, 1962.

13. Selman, J. R., Tobias, C. W., Mass transfer Measurement by the Limiting Current Technique, Adv. Chem. Eng., 1978, 10, 211-318.

14. Ko, S. H., Moon, K. W. and Chung, B. J., Applications of Electroplating Method for Heat Transfer Studies Using Analogy Concept, Nuclear Engineering and Technology, 2006, 38, 251-258.

15. Kang, K. U. and Chung, B. J., The Effects of the Anode size and Position on the Limiting Currents of Natural Convection Mass Transfer Experiment in a Vertical Pipe, Trans. of the KSME(B), 2010, 34, 1-8.

16. Fenech, E. J. and Tobias, C. W., Mass transfer by free convection at horizontal electrode, Electrochimica Acta, 1960, 2, 311-325. 